\title{
Effects of rate, temperature and absorption of organic solvents on the fracture of plain and glass-filled polystyrene
}

\author{
Y.W.MAI ${ }^{*}$, A. G. ATKINS ${ }^{\dagger}$ \\ Department of Mechanical Engineering, University of Michigan, Ann Arbor, Michigan, \\ USA
}

The rate/temperature dependent fracture behaviour of plain and glass-filled polystyrene has been investigated over the crack speed $(\dot{a})$ range of $10^{-6}$ to $10^{-2} \mathrm{~m} \mathrm{sec}^{-1}$ and in the temperature $(T)$ range of 296 to $363 \mathrm{~K}$. The $K_{\mathrm{c}}(\dot{a}, T)$ relationships obtained, where $K_{\mathrm{c}}$ is the stress intensity factor at fracture, are shown to follow those given by the Williams/ Marshall relaxation crack growth model and the toughness-biased rate theory. Crack propagation in both materials is shown to be controlled by a $\beta$-relaxation molecular process associated with crazing. Crack instabilities observed in plain polystyrene are analysed successfully in terms of isothermal-adiabatic transitions at the crack tip.

Fracture initiation experiments are also conducted in which the effects of organic liquids on the fracture resistances of both plain/glass-filled polystyrene have been determined. Good correlations between $K_{i}^{2}\left(K_{i}\right.$ being the crack initiation stress intensity factor) and $\delta_{\mathrm{s}}$, solvent solubility parameter, of various liquid environments have been obtained, which give a minimum $K_{\mathrm{i}}^{2}$ value at $\delta_{\mathrm{s}} \approx \delta_{\mathrm{p}}$, where $\delta_{\mathrm{p}}$ is the solubility parameter of the polymer. For a given temperature, liquid environment and crack speed, the glass-filled polystyrene is shown to possess greater resistances to crack propagation than plain polystyrene.

\section{Introduction}

The resistance to crack initiation and subsequently crack propagation of solids, especially viscoelastic glassy polymers, is dependent on temperature $(T)$, crack speed $(\dot{a})$ and absorption of liquid environments. For PMMA in particular, the effects of these variables on fracture toughness have been extensively studied in the last few years [1-7], the results being successfully interpreted using the concepts of elastic fracture mechanics. Also, chemical rate theory analyses have been successfully applied to fracture data to give, among other things, activation energies for the particular mol- ecular fracture process that is taking place. These analyses are either of simple Arrhenius form [8] or fracture toughness $(R)$ biased [7] (or stress intensity factor $(K)$ biased) [9] Ree-Eyring relationships.

The tensile strength $(\sigma)$ or brittle polymers can be increased by reinforcing with strong fibres which may be either continuous or discontinuous, and orderly or randomly oriented. Considerable analytical and experimental research has been devoted to determine composite tensile strengths and composite moduli of such fibre-reinforced polymers $[10-17]$, but fewer investigations have

\footnotetext{
*Present address: Department of Mechanical Engineering, Imperial College of Science and Technology, Exhibition Road, London, UK.

$\dagger$ Present address: Delta Materials Research, Ltd., Box 22, Hadleigh Road, Ipswich, Suffolk, UK.
} 
been directed towards the measurement of fracture toughness. To our knowledge, there have been no publications dealing with the fracture properties of thermoplastics randomly reinforced with short glass fibres, under the combined effects of crack speed, temperature and hostile liquid environments.

We have chosen to investigate polystyrene filled with randomly oriented short $(<6 \mathrm{~mm})$ glass fibres, the fraction of which was $20 \%$ by weight. Plain polystyrene is particularly sensitive to organic solvents (such as benzene, toluene, carbon tetrachtoride, methanol, ethanol, isopropanol and water), whereby its resistance to crazing or cracking is severly reduced [18]. Thus, in addition to determining toughness, as functions of crack speed and temperature, for both plain and glass-filled polystyrene, we have investigated whether the toughness of the glass-filled polystyrene is affected to the same extent by the same organic solvents. Correlations between the initiation fracture toughness $\left(R_{\mathrm{i}}\right)$ and the solubility parameter of the solvent $\left(\delta_{s}\right)$ will be presented and discussed. Microscopic examinations of the fracture surfaces produced in the various liquid organic solvents have also been studied to give better insight into the fracture mechanisms occurring in the different solvents.

We have also examined all our results in terms of the various rate process relationships already used for plain polymers, in order to see whether the glass reinforcement affects the factors controlling toughness.

\section{Experiments and derivations}

$6 \mathrm{~mm}$ chopped E-glass fibres, were used as the reinforcing medium. This fibreglass has a tensile strength of about $1.38 \mathrm{GN} \mathrm{m}^{-2}$ with a diameter of $10 \mu \mathrm{m}$, and a $(l / d)$ aspect ratio of 625 . The polysytrene was a general purpose grade product of the Monsanto (USA) Company. Ready-mixed glassreinforced polystyrene pellets (glass $20 \%$ by weight) were supplied through the courtesy of Thermofil Company (Michigan, USA), from which standard dumb-bell shape tensile specimens with dimensions shown in Fig. 1 were injection moulded in our own laboratory; the preheat temperature was $433 \mathrm{~K}$, injection temperature $517 \mathrm{~K}$ and injection pressure $10 \mathrm{MN} \mathrm{m}^{-2}$. Plain polystyrene

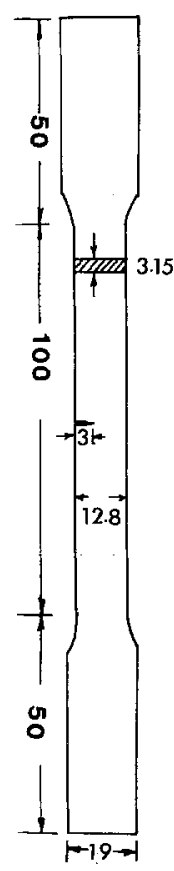

Figure 1 An SEN specimen (all dimensions in $\mathrm{mm}$ ).

tensile specimens were also prepared in a similar way.

The dumb-bell specimens were easily converted into single-edge-crack fracture toughness tensile specimens. Starter cracks were made in the specimens firstly with a jeweller's saw to approximately the required length, and then by notching with a razor blade*. In all specimens, the starter crack length was fixed at $3 \mathrm{~mm}$ which therefore gave an effective constant $a / W$ ratio of about 0.234 . Lack of suitable equipment on the injection moulder prevented us from making different, and arguably more satisfactory, toughness specimens such as the compact tension geometry.

Experiments were performed using an Instron testing machine with cross-head speeds varying between $8.33 \mu \mathrm{m} \mathrm{sec}^{-1}$ and $2 \mathrm{~mm} \mathrm{sec}^{-1}$. Temperatures were varied between 213 and $363 \mathrm{~K}$, the actual temperatures of the specimens being measured with a copper-constantan thermocouple during the tests.

By noting the starter crack length, the fracture load at the instant of crack initiation (observed through a travelling microscope), the final crack length (infered from the fracture surface) and the final fracture load at crack instability, it is possible to obtain the corresponding initiation and insta-

\footnotetext{
* It was shown in [20] that the notching technique was critical in determining the $K_{\mathrm{c}}(\dot{a})$ relationship. In the present series of experiments, to be consistent, all starter cracks were razor notched.
} 
bility stress intensity factors, $K_{\mathbf{i}}$ and $K_{\mathrm{f}}$ by the following equation $\dagger[19]$

$$
K_{\mathrm{c}}=\sigma \sqrt{ } a Y=\frac{X}{t W} \sqrt{ } a Y
$$

where $t, W$ are thickness and width of specimen, $a$, current crack length, and $X$, the load at fracture instability or initiation. $Y$ is a finite width correction factor and is a function of $(a / W)$ [19]. When the rate/temperature-dependent Young's modulus is known (see Section 3.1) $K_{\mathrm{c}}$ can be converted to equivalent fracture toughness $(R)$ values by $E R=$ $K_{\text {c }}^{2}$.

Because the SEN specimen has a bad geometric stability factor [7], and therefore displays little, if any, slow crack growth before instability, it is difficult to measure experimentally the crack velocity in the early stages of growth. However, Williams et al. [21] and Marshall et al. [20] have successfully employed the concept of an apparent crack speed ( $\left.\dot{a}_{\text {app }}\right)$ determined from the analytical expressions for crack tip stress rate owing to Irwin [22] or crack tip strain-rate owing to Williams [23]. Arguing that there must be continuity in strain-rate at crack initiation, $\dot{a}_{\text {app }}$ is obtained by equating two separate expressions for the crack tip strain-rate of a stationary crack and that of a moving crack. Then

$$
\dot{a}_{\mathrm{app}}=\frac{1}{\sqrt{2 \pi t_{\mathrm{f}}}}\left(\frac{K_{\mathrm{c}}}{\sigma_{\mathrm{y}}}\right)^{2}
$$

where $\sigma_{\mathrm{y}}$ is the yield strength and $t_{\mathrm{f}}$ the time to fracture initiation during the cracking experiment. Good agreement between $\dot{a}$ calculated from Equation 2 and crack speeds measured by high speed photography have been reported by Williams $e t$ al. [21] and Marshall et al. [20] for crack propagation in PMMA and polystyrene. In this same way, we generated many $\left(K_{\mathbf{c}}, \dot{a}\right)$ data. Note that use of Equation 2 requires independent $\sigma_{\mathrm{y}}(T, \dot{\epsilon})$ information.

Other cracking experiments were performed in the presence of organic solvents including benzene, toluene, carbon tetrachloride, methanol, ethanol, isopropanol and water. These liquids are known to "attack" polystyrene in varying degrees. The liquid environments were maintained at the crack tip region by using squeeze bottles. These exploratory environmental fracture tests were conducted only at $296 \mathrm{~K}$ with a machine cross-head speed of $8.33 \mu \mathrm{m} \mathrm{sec}^{-1}$.

\section{Results and discussion}

\subsection{Rate-temperature dependent fracture of plain polystyrene}

Fig. 2 shows the $K_{\mathrm{c}}(\dot{a})$ relationship for plain polystyrene for temperatures of $298 \mathrm{~K}$ and above. It is seen that at a given $T$, crack speeds are usually higher for larger $K_{\mathrm{c}}$ values and are lower for lower temperatures at a given magnitude of $K_{\mathrm{c}}$. At a given temperature, for a broad range of crack speeds, $\left(10^{-6}\right.$ to $\left.10^{-2} \mathrm{~m} \mathrm{sec}^{-1}\right)$, the $\log K_{\mathrm{c}}-\log \dot{a}$ plot gives a slope of about 0.12 . (This slope appears to be



Figure 2 Relations between stress intensity factor and crack speed for plain polystyrene.

$\dagger$ There has been some concern over the use of this linear elastic fracture mechanics stress intensity factor for the glassfilled composite material. However, results in this work and in [17] show that such $K$-formulae, if not exact, are acceptable. The subscript " $c$ " can be identified as " $i$ " or " $f$ " as the case may be. 
more or less constant for all the temperatures involved.)

In calculating the apparent crack speeds from Equation 2, it is required to know the functional relationship between $\sigma_{\mathrm{y}}, \dot{\epsilon}$ and $T$. The dependence on $T$ between 296 and $363 \mathrm{~K}$ has been determined independently, and in general, $\sigma_{\mathbf{y}}$ is found to increase with strain-rate $(\dot{\epsilon})$ and decrease with increasing temperature.

Let us analyse these $K_{\mathbf{c}}(\dot{a})$ results in terms of a recent relaxation crack growth model due to Williams and Marshall [1] and also a toughnessbiased rate theory for crack propagation used by Atkins et al. [7]. For relaxation controlled crack growth, Williams and Marshall [1] give the following $K_{\mathrm{c}}(\dot{a})$ relationship

$$
K_{\mathbf{c}}=C a^{\frac{m+n}{2(1-m+n)}}
$$

where $m, n$ are measures of the time dependent response of yield stress and modulus respectively, and $C$ is a constant, being a function of crack tip opening displacement (C.O.D.), unit time values of the Young's modulus $\left(E_{0}\right)$ and yield stress $\left(\sigma_{0}\right)$. For many polymeric materials, $m$ and $n$ are about the same magnitude $(\sim 0.10)$, so that a $\log K_{\mathrm{c}}$ versus $\log \dot{a}$ plot should give a theoretical slope of approximately 0.10 . The actual slopes of 0.10 to 0.12 in Fig. 2 are, therefore, in good agreement with the theoretical value.

Notice that in the Williams-Marshall analysis, it is assumed that the C.O.D. should be essentially constant for each region of crack growth, and independent of rate and temperature. In PMMA this appears to be the case (COD $\simeq 7 \mu \mathrm{m}$ for $243 \mathrm{~K}$ $<T<343 \mathrm{~K}$ ), but the present data sugest otherwise for polystyrene. Values of C.O.D. may be estimated from the following equation where

$$
\text { C.O.D. }=R / \sigma_{\mathrm{y}}=K_{\mathrm{c}}^{2} /\left(E \sigma_{\mathrm{y}}\right)
$$

Since $E$ and $\sigma_{\mathrm{y}}$ are crack tip quantities and depend on effective crack tip speed and temperature, we have to find an expression for $E$ as a function of crack tip strain-rate $(\dot{\epsilon})$ and temperature $(T)$. By running standard tensile tests at different strainrates $\left(10^{-5} \mathrm{sec}^{-1}<\dot{\epsilon}<10^{-2} \mathrm{sec}^{-1}\right)$ and temperatures, we found that $E(\dot{\epsilon}, T)$ data for polystyrene could be reasonably represented by

$$
E=D \dot{\epsilon}^{0.055}\left(\mathrm{GN} \mathrm{m}^{-2}\right)
$$

where $D$ is a constant depending on temperature. For example, $D=3.734,3.253,2.722$ and 2.34 for $T=298,323,343$ and $363 \mathrm{~K}$ respectively. Irwin [22] and Williams [23] have given expressions for rates at the crack tip, the first in terms of stress rate and the second in terms of strain-rates. In particular, for a moving crack, the effective crack tip strain-rate $(\dot{\epsilon})$ is given by [23]

$$
\dot{\epsilon} \approx \pi \epsilon^{3}\left(E / K_{\mathrm{c}}\right)^{2} \dot{a} .
$$

For a given temperature, and a combination of $\dot{a}$ and $K_{\mathrm{c}}, \dot{\epsilon}$ can be solved numerically by using Equation 5 and making a suitable guess ${ }^{*}$ for $\epsilon$. Hence, knowing $\dot{a}, K_{\mathbf{c}}, E(\dot{a})$ and $\sigma_{\mathrm{y}}(T, \dot{\epsilon})$, it is possible to solve for C.O.D. as given in Equation 4. For example, consider $T=343 \mathrm{~K}, K_{\mathrm{c}}=1.25 \mathrm{MN}$ $\mathrm{m}^{-3 / 2}, \dot{a}=1.9 \times 10^{-5} \mathrm{~m} \mathrm{sec}^{-1}, \epsilon=0.015$, we have

$$
\dot{\epsilon} \approx 1.29 \times 10^{-4} E^{2}\left(\mathrm{sec}^{-1}\right) \text {. }
$$

Solving this and equation 6 , we obtain $\dot{\epsilon} \approx 4 \times 10^{-4}$ $\mathrm{sec}^{-1}$ and $E=1.78 \mathrm{GN} \mathrm{m}^{-2}$. Also, at this effective crack tip strain-rate, $\sigma_{\mathrm{y}} \approx 28.0 \mathrm{MN} \mathrm{m}^{-2}$. Hence,

$$
\text { C.O.D. }=\frac{1.25^{2} \times 10^{-3}}{1.78 \times 28.0} \mathrm{~m} \approx 31.35 \mu \mathrm{m} \text {. }
$$

Similar calculations show that the C.O.D. values for $T=363,323$ and $298 \mathrm{~K}$ are respectively 33.5 , 42.0 and $50 \mu \mathrm{m}$. These results suggest that, although at a given temperature the C.O.D. may have a constant magnitude which is independent of crack speed, the C.O.D. does increase with decreasing temperature. This observation appears to be in disagreement with the assumption of a tempersture independent C.O.D. fracture criterion of Williams and Marshall [1]. Of course these critical crack tip opening displacements would be different were $\epsilon$ to assume other values. For $\epsilon<0.01$, C.O.D. magnitudes would be greater; e.g. if $\epsilon=$ $0.005, \dot{\epsilon}=10^{-5}\left(\mathrm{sec}^{-1}\right), \quad E=1.40 \mathrm{GN} \mathrm{m} \mathrm{m}^{-2}$, C.O.D. $=46.5 \mu \mathrm{m}$ at $343 \mathrm{~K}$.

Let us now analyse these $K_{\mathrm{c}}(a)$ data again but in terms of the toughness-biased rate theory [7]. A recent paper of one of us [7] shows that the rate/temperature-dependent fracture process of PMMA may be described by

$$
\dot{a}=A \exp \left[\frac{-U+\lambda R}{k T}\right]
$$

where $A$ is a constant; $U$, the activation energy for

* $\epsilon$ is the yield strain defined by $\sigma_{\mathbf{y}} / E$, where both $\sigma_{\mathbf{y}}$ and $E$ are functions of temperature and effective crack tip strainrate. A few calculations show that $\epsilon \approx 0.015$ for all temperatures. 
the fracture process involved; $k$, Boltzmann's constant; and $\lambda$ the activation area. Such a toughnessbiased Ree-Eyring activation equation has been used to describe fracture in glasses [24, 36, 37]. Substituting $R=K_{\mathrm{c}}^{2} / E$ and dropping the Poisson's ratio term,

$$
\dot{a}=A \exp \left[-\frac{U}{k T}+\frac{\lambda}{k} \cdot\left(\frac{K_{\mathrm{c}}^{2}}{E T}\right)\right]
$$

so that

$$
\ln \dot{a}=\ln A-\frac{U}{k T}+\frac{\lambda}{k} \cdot\left(\frac{K_{\mathrm{c}}^{2}}{E T}\right) .
$$

Therefore, straight lines with slopes $(\lambda / k)$ should be obtained if $\ln \dot{a}$ is plotted against $K_{\mathrm{c}}^{2} / E T$. Since both $K_{\mathbf{c}}$ and $E$ are dependent on $\dot{a}$, we have to use Equations 5 and 6 for our conversion. The results are shown in Fig. 3. It may be seen that the correlation between $\dot{a}$ and $K_{\mathrm{c}}^{2} / E T=(R / T)$ is reasonably good. However, slope transitions are observed for temperatures above $323 \mathrm{~K}$. Depending on the $\dot{a}$ value chosen, different sets of $(\lambda, U)$ values can be obtained. For example, for $\dot{a}=10^{-3}$ and $10^{-5}$ $\mathrm{m} \mathrm{sec}{ }^{-1}$ respectively, we have $\left(4.4 \mathrm{~m}^{2} \mathrm{~mol}^{-1}, 87\right.$ $\left.\mathrm{kJ} \mathrm{mol}{ }^{-1}\right)$ and $\left(30 \mathrm{~m}^{2} \mathrm{~mol}^{-1}, 220 \mathrm{~kJ} \mathrm{~mol}^{-1}\right)$. Physically, this suggests that both the activation energy and activation area are crack-speed dependent. A similar observation has also been reported by Brady and Yeh [25], who have found that in some glassy polymers, such as PMMA and PS, the activation energy and activation volume are strain-rate and temperature dependent. The activation energy values reported here, i.e. 87 to $220 \mathrm{~kJ} \mathrm{~mol}^{-1}$, are not unreasonable magnitudes for a $\beta$-relaxation process to occur in polystyrene [25].

By making a similar analysis as given in $[7,24]$, we have calculated the energy $(\beta R)$ required to break the unit area of bonds in the crack plane, where

$$
\beta=\frac{\lambda}{d_{0}^{2}} \frac{1}{N}
$$

$N$ is the Avogadro number $\left(=6 \times 10^{23}\right.$ per mole) and $d_{0}$ the atomic spacing of the bonds. By assuming the chain to chain spacing $\left(d_{0}\right)$ to be $1 \mathrm{~nm}$, $\beta \approx(0.8$ to 5$) \times 10^{-5}$ for $\lambda \approx 5$ to $30 \mathrm{~m}^{2} \mathrm{~mol}^{-1}$. Hence, the work required to break the bonds per unit area of the polymer becomes approximately 0.008 to $0.05 \mathrm{~J} \mathrm{~m}^{-2}$ when $R \approx 1 \mathrm{~kJ} \mathrm{~m}^{2}$. The order of these magnitudes agrees very well with that necessary to break the Van der Waal's bonding of the chain to chain segments for polystyrenet [26].

So far, we have shown that basically, these

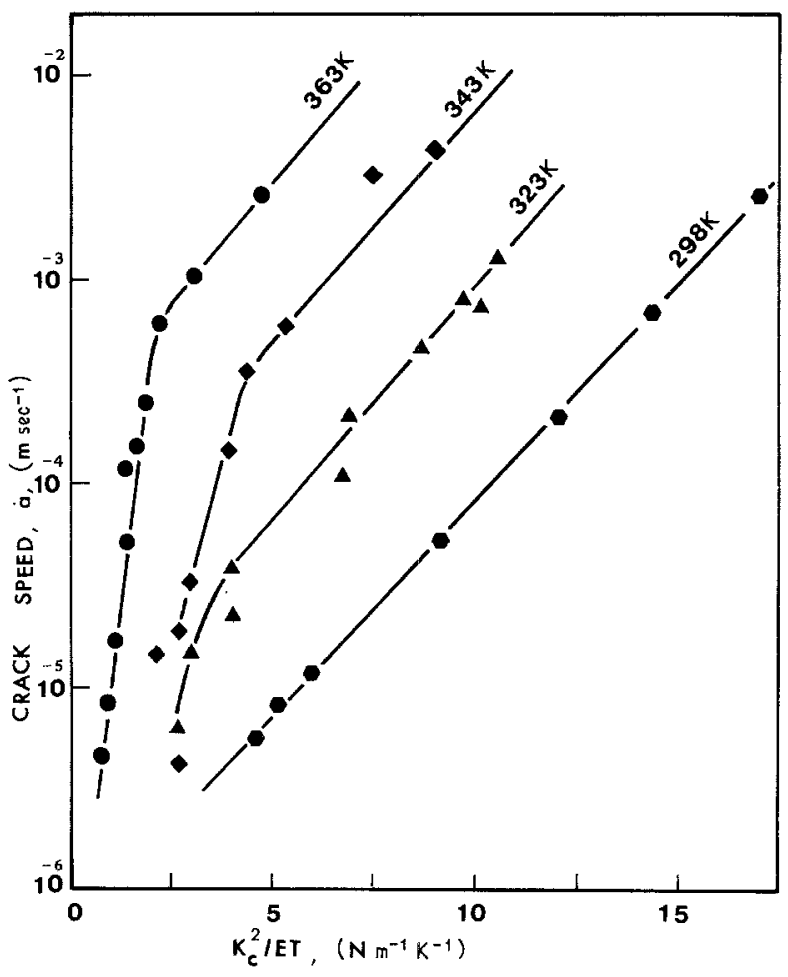

Figure 3 Plain polystyrene, crack speed against $K_{\mathrm{c}}^{2} / E T$.

$\dagger$ In a private communication with Yeh [26], this magnitude should be 0.007 to $0.07 \mathrm{~J} \mathrm{~m}^{-2}$. 
$K_{\mathrm{c}}(\dot{a})$ experimental results can be analysed adequately with either the Williams/Marshall theory or the toughness-biased rate equation. It has been frequently the practice to draw $K_{\mathrm{c}}(\dot{a})$ diagrams in semi-logarithmic plots when experimental data concerning ceramics and glass are analysed [27, 28]. In the following, we shall proceed to show that the success of such correlations is based on two assumptions: (1) the crack propagation is rate controlled and toughness biased; and (2) the C.O.D. and $\epsilon$ are invariant with crack speed and temperature.

By noting that $K_{\mathrm{c}} / E=\sqrt{ }($ C.O.D. $\epsilon)$, and rewriting Equation 9, we have

$$
\ln \dot{a}=\ln A-\frac{U}{k T}+\frac{\lambda}{k} \cdot \sqrt{ }(\text { C.O.D. } \epsilon)\left(\frac{K_{\mathrm{c}}}{T}\right) \text {. }
$$

When the product of C.O.D. and $\epsilon$ is a constant, the $\ln \dot{a}$ versus $\left(K_{\mathrm{c}} / T\right)$ plots should give straight lines with slopes equal to $[(\lambda / k) \sqrt{ }($ C.O.D. $\epsilon)]$. Note that if the C.O.D. varies with temperature, the slopes would not be the same. Similar slope changes could also occur if $\lambda$ or $\epsilon$ are also varying with temperature. Fig. 4 shows these $K_{\mathrm{c}}(\dot{a})$ plots according to Equation 11. Clearly, fairly good correlations still exist for any given temperature but the slopes of the straight lines are not identical.
Interpreting these data from Equation 11 gives $U=140$ to $220 \mathrm{~kJ} \mathrm{~mol}^{-1}$ and $\lambda \approx 26 \mathrm{~m}^{2} \mathrm{~mol}^{-1}$. These results are close to those predicted (based on $\dot{a} \approx 10^{-5} \mathrm{~m} \mathrm{sec}^{-1}$ ) using Fig. 3 and Equation 9 .

\subsection{SEN instability in plain polystyrene}

The instabilities observed in the $K_{\mathbf{c}}(\dot{a})$ data shown in Fig. 2 are similar to those observed in PMMA [3, 7]. Since the SEN instability $K_{\mathrm{c}}$ values are increasing functions of cross-head speed, (as obtained in this work and that of Marshall et al. [20], the maximum values at each temperature is used in Fig. 2, which on intersecting the extension of the $K_{\mathrm{c}}(\dot{a})$ lines will give the SEN instability crack velocities*.

It is thought, in much the same way, that these instability $\left(K_{\mathrm{c}}, \dot{a}\right)$ data can be analysed as given by Marshall et al. [3], on the assumption of an isothermal-adiabatic transition during crack propagation at these high speeds. Thus, following the same arguments in [3], the instability crack velocity is given by

$$
\dot{a}=\frac{(\Delta T)^{2} \rho c \bar{k}}{\epsilon^{2} K_{\mathrm{c}}^{2}}
$$

where

$$
\Delta T=\left(\bar{T}-T_{0}\right)=(2 k / U) \bar{T}^{2}
$$

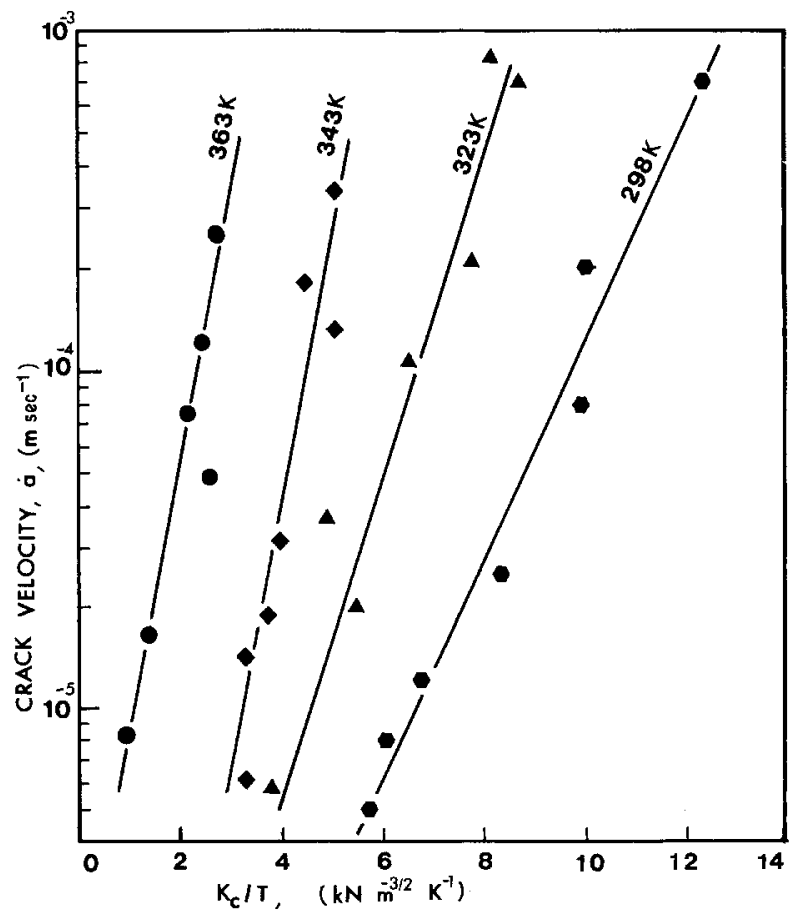

Figure 4 Plain polystyrene, crack speed against $K_{\mathrm{c}} / T$.

\footnotetext{
* A discussion on the general problem of crack stability and in particular SEN instabilities has been given in [7].
} 
Note that $\bar{T}$ is the temperature at the crack tip necessary to cause crack instability; $T_{0}$ is the test temperature; $\rho$ the density of polystyrene; $c$, the specific heat and $\bar{k}$, the thermal conductivity of the polymer.

TA B LE I Calculated crack instability velocities, temperature rise and measured instability velocity

\begin{tabular}{lccc}
\hline $\begin{array}{l}T_{\mathrm{o}} \\
(\mathrm{K})\end{array}$ & $\begin{array}{l}T-T_{0} \\
\left({ }^{\circ} \mathrm{C}\right)\end{array}$ & $\begin{array}{l}a \text { (theory) } \\
\left(\mathrm{mm} \mathrm{sec}^{-1}\right)\end{array}$ & $\begin{array}{l}\dot{a} \text { (measured) } \\
\left(\mathrm{mm} \mathrm{sec}^{-1}\right)\end{array}$ \\
\hline 298 & 7.40 & 1.34 & 3.00 \\
323 & 8.80 & 3.26 & 5.00 \\
343 & 9.00 & 6.85 & 10.00 \\
363 & 12.00 & 30.00 & 13.00 \\
\hline
\end{tabular}

Table I gives the values for $\Delta T$ and $\dot{a}$ at instability calculated from Equation 12, using the following values for the physical variables: $U / k=2.5 \times$ $10^{4} \mathrm{~K}, \epsilon \approx 0.015, K_{\mathrm{c}}=$ instability value at each temperature as shown in Fig. $2, \rho \approx 1.05 \mathrm{~g} \mathrm{~cm}^{-3}$, $c \approx 10^{-3} \times T_{0} \mathrm{cal}^{\circ} \mathrm{C}^{-1} \mathrm{~g}^{-1}\left(T_{0}\right.$ in $\left.\mathrm{K}\right), \bar{k} \approx 2.5 \times 10^{-4}$ cal $\mathrm{cm}^{-1}{ }^{\circ} \mathrm{C}^{-1} \mathrm{sec}^{-1}$.

Fig. 5 shows these results, and it may be seen that the experimental values are often greater than the theoretical predicted magnitudes based on the isothermal-adiabatic transition. A good fit of the experimental data may be obtained when $K_{\mathrm{c}} \approx$ $2.0 \mathrm{MN} \mathrm{m}^{-3 / 2}$.
3.3. Rate-temperature dependent fracture in glass-filled polystyrene

\subsubsection{Dependence of $K_{\mathrm{i}}$ and $K_{f}$ on temperature}

Both $K_{\mathrm{i}}$ and $K_{\mathrm{f}}$ are affected by temperature, and at a cross-head rate of $8.33 \mu \mathrm{m} \mathrm{sec}^{-1}$, their relationships are shown in Fig. 6. For the temperature range of 213 to $396 \mathrm{~K}$, as expected $K_{\mathbf{i}}$ increases gradually with decreasing temperature. In contrast to the fracture behaviour of PMMA $[3,7]$ and plain polystyrene (see Fig. 2) where $K_{\mathrm{f}}$ increases with reducing temperature, the reverse relation is however observed here for the glass-filled poly stryene. It is surmised that since longer pull-out of glass fibres were observed at higher temperatures, the fracture toughness of the composite could be bigger and thus cause a $d K_{\mathbf{f}} / d T>0$ phenomenon.

It should be noted that for temperatures greater than $323 \mathrm{~K}$, it is impossible to identify the critical crack length from the fractured surfaces, because there is no transition between slow stable and catastrophic fast crack propagation, as has been observed for lower temperature fractures. Consequently, no $K_{\mathrm{f}}$ data has been shown on Fig. 6 for these temperatures. It could also be projected from the same figure that at even lower temperatures, say $193 \mathrm{~K}, K_{\mathrm{i}}$ and $K_{\mathrm{f}}$ might coincide which would result in no stable crack growth region whatever on the fracture surface. Unfortunately, owing to

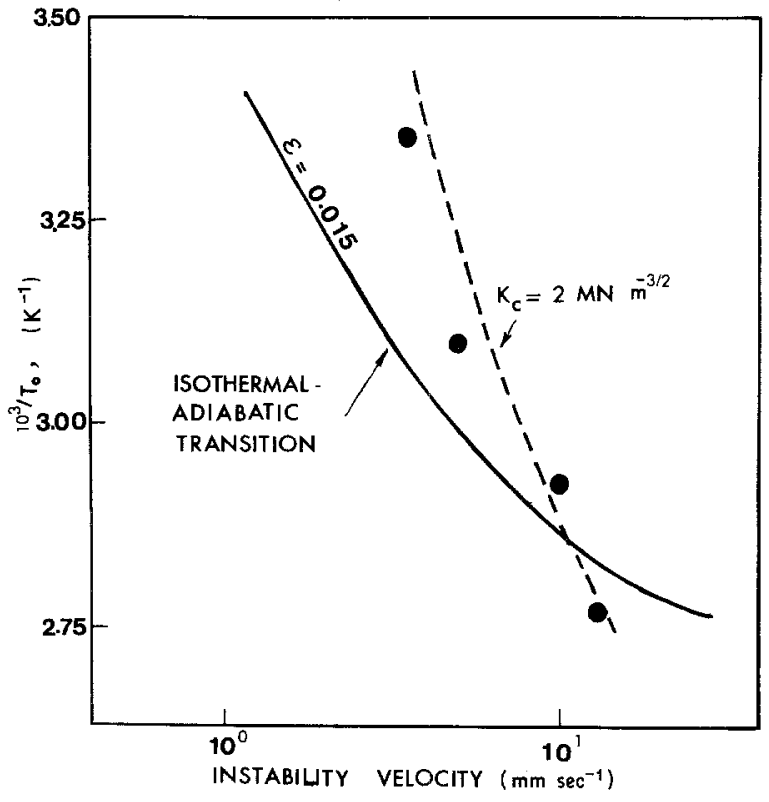

Figure 5 Crack speeds at instability in plain polystyrene. 


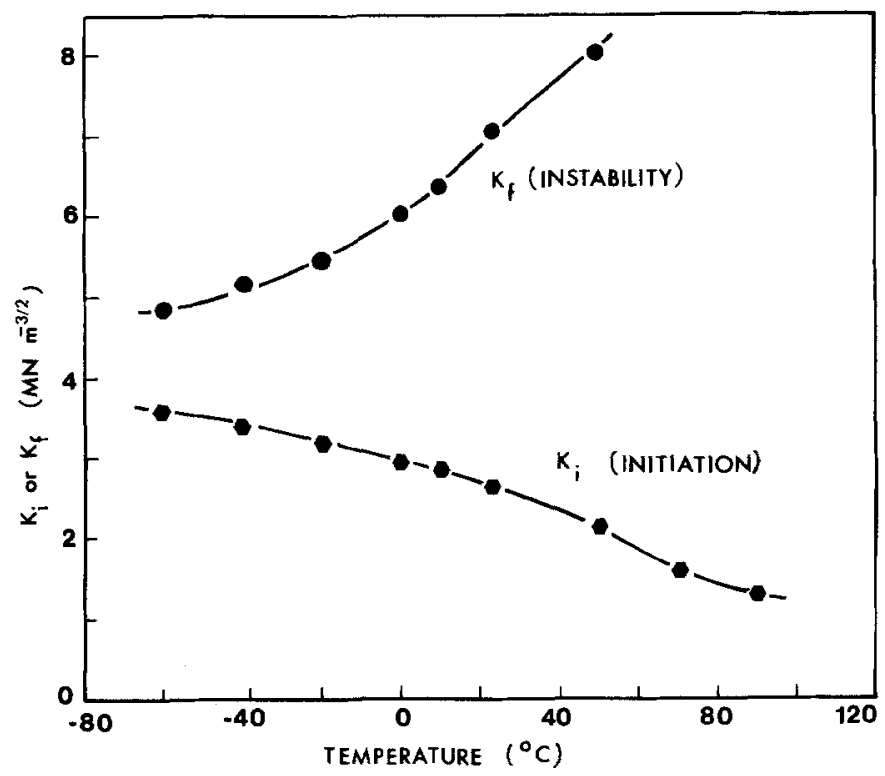

Figure 6 Variations of stress intensity factors at initiation and instability with temperature for glass-filled PS. the limitations of our "environmental chamber", we could not get down to this low temperature and verify our projection.

\subsubsection{Fracture toughness, crack speed and temperature relationships}

Fig. 7 shows the $K_{\mathrm{c}}(\dot{a})$ relationship for the glassfilled polystyrene for temperatures of 296 to $363 \mathrm{~K}$. It is seen that a given $T$, for a broad range of crack speeds $\left(10^{-3}\right.$ to $\left.1 \mathrm{~mm} \mathrm{sec}^{-1}\right)$, the $\log -\log$ plot gives a slope of about 0.07 to 0.08 . This slope appears to be more or less constant for all the temperatures involved, and is in excellent agreement with the predicted slope of 0.10 according to the Williams/ Marshall equation. It should be noted that both $m$ and $n$ should be decreased by the presence of the glass fibres so that the theoretical slope should be less than 0.10 which, therefore, becomes an upperbound slope. Before reaching the SEN instabilities, slope transitions have been observed in these $\log$ $K_{\mathbf{c}}-\log \dot{a}$ plots.

By repeating the same analysis given in Section 3.1 , and with $E=E^{*}(\dot{\epsilon}, T)$ and $\sigma_{\mathrm{y}}=\sigma_{\mathrm{y}}(\dot{\epsilon}, T)$ experimentally established, we have found that for $T$ between 296 and $363 \mathrm{~K}$, the C.O.D. values are 12.0 to $20 \mu \mathrm{m}$ while $\epsilon \approx 0.012 \dagger$. These crack

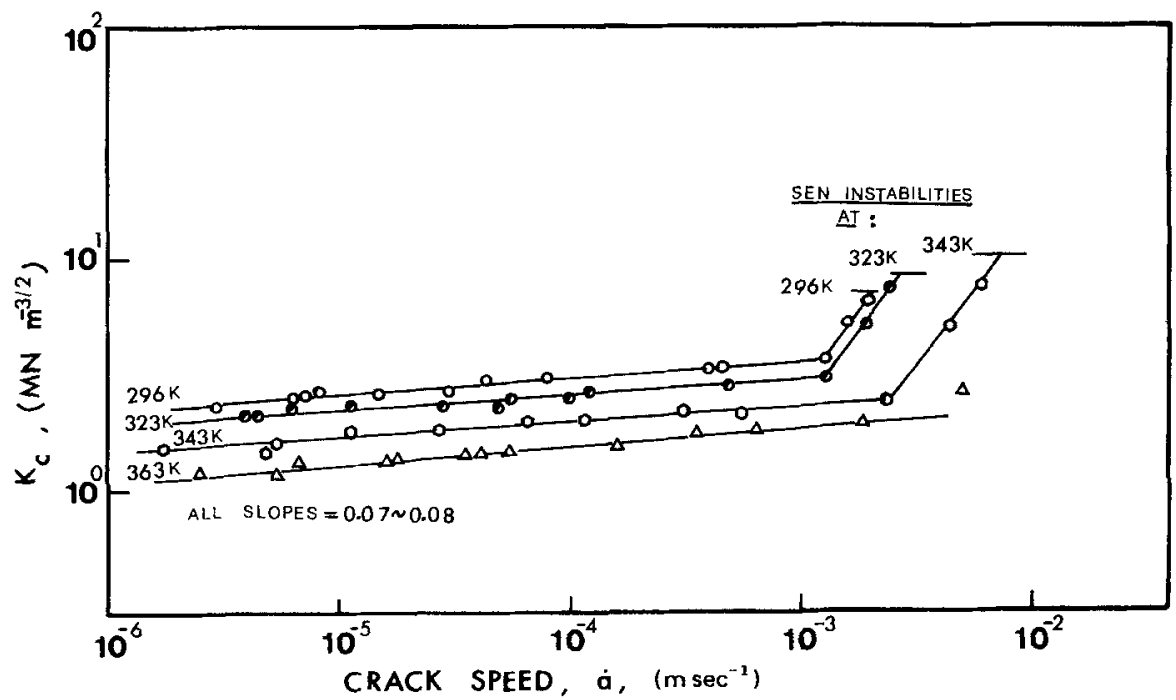

Figure 7 Relations between stress intensity factor and crack speed for glass-filled PS.

* An approximation to experimental data is described by, $E=12.5 \dot{\epsilon}^{0.05}-0.0162 T / \mathrm{GN} \mathrm{m}^{-2}$ ).

$\dagger_{\epsilon}$ for glass-filled PS $=0.012$ to 0.014 for all temperatues investigated. In these calculations, $\epsilon=0.012$ is assumed. 
opening values are smaller than the plain polystyrene.

The raw data from Fig. 7 may be reinterpreted in terms of the toughness-biased rate theory. These results are shown in Fig. 8 . It may be seen that plotting $\ln \dot{a}$ versus $K_{\mathrm{c}}^{2} / E T(=R / T)$ also gives

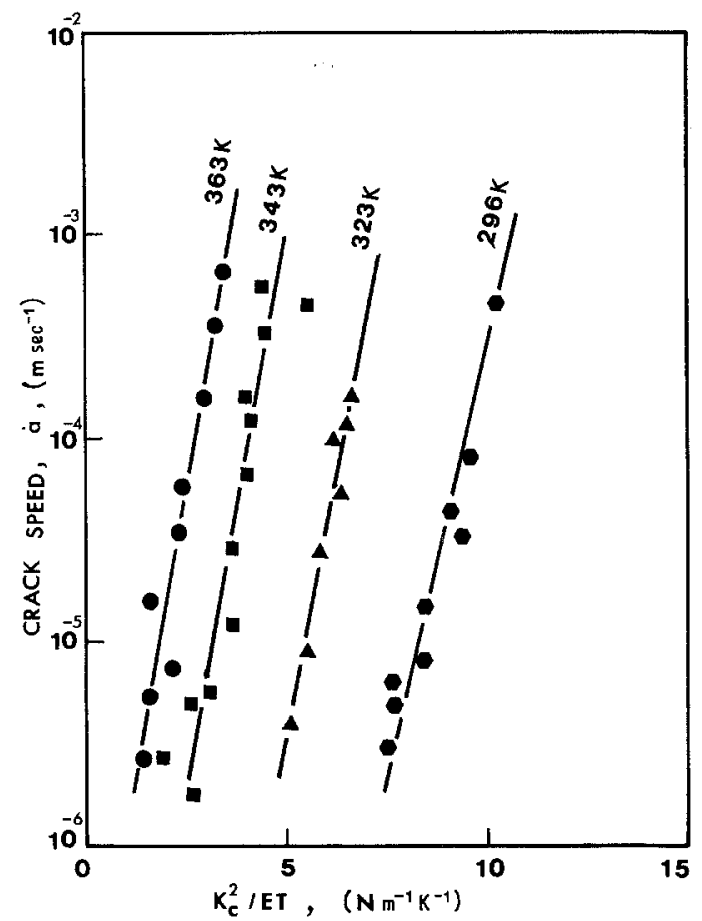

Figure 8 Glass-filled PS, crack speed against $K_{\mathrm{c}}^{2} / E T$. straight lines according to Equation 8 . The activated area $(\lambda)$ and activation energy $(U)$ calculated from these plots are $22 \mathrm{~m}^{2} \mathrm{~mol}^{-1}$ and $200 \mathrm{~kJ} \mathrm{~mol}^{-1}$ respectively.

It is also interesting to find out that the same $K_{\mathrm{c}}(\dot{a})$ data also fit Equation 11 equally well. These plots (not presented here) are similar to Fig. 4 for the plain polystyrene. Although there is more scatter in the data as $T$ decreases, for all practical purposes, the slopes $[=(\lambda / k) \sqrt{ }($ C.O.D. $\epsilon)]$ may be regarded as having a constant value. By substituting $\epsilon=0.012$ and appropriate C.O.D. values at a given temperature into Equation 11 , $\lambda$ can be calculated from the measured slopes. A few calculations show that $\lambda \approx 21$ to $28 \mathrm{~m}^{2} \mathrm{~mol}^{-1}$. By cross-plotting, the activation energy is found to be some $190 \mathrm{~kJ} \mathrm{~mol}^{-1}$. This magnitude agrees very well with that calculated from the $\ln \dot{a}-K_{\mathrm{c}}^{2} / E T$ plot $\left(200 \mathrm{~kJ} \mathrm{~mol}^{-1}\right)$. It appears, therefore, that the fracture process in the glass-filled polystyrene is also governed by the $\beta$-relaxation process of the matrix material.

\section{Fracture initiation in liquid organic solvents}

Fig. 9 shows the correlation between $K_{\mathrm{i}}^{2}$ for the glass-filled polystyrene with the solvent solubility parameter $\left(\delta_{\mathrm{s}}\right)$ of the various liquid solvents used $\neq$. The curve is similar to that reported by Andrews and Bevan [30] for PMMA in a series of aliphatic

Figure 9 Variations of $K_{1}^{2}$ and solvent solubility parameter $\left(\delta_{\mathbf{s}}\right)$ for plain and glass-filled PS. $1=$ toluene, 2 = benzene, 3 = acetone, $4=$ isopropanol, $5=$ ethanol, and $6=$ methanol. Instron cross-head rate $\approx 8.33 \mu \mathrm{m} \mathrm{sec}^{-1}$ and temperature $=296 \mathrm{~K}$.

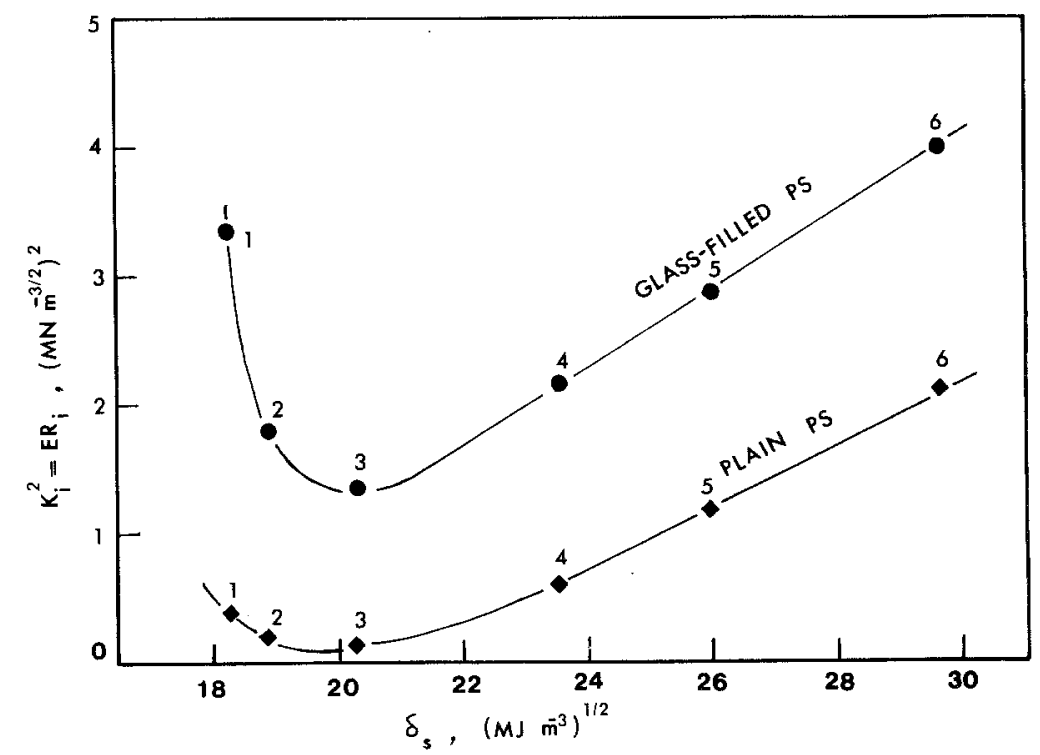

\$ The solvent solubility parameters of the various liquid environments are given in Table II. These values are quoted from [29]. 
TABLE II Solvent solubility parameter $\left(\delta_{\mathrm{s}}\right)$ of various liquid environments

\begin{tabular}{ll}
\hline Environment & $\delta_{\mathrm{s}}\left(\mathrm{MJ} \mathrm{m}^{-3}\right)^{1 / 2}$ \\
\hline Carbon tetrachloride & 17.64 \\
Toluene & 18.23 \\
Benzene & 18.90 \\
Acetone & 20.50 \\
Isopropanol & 23.58 \\
Ethanol & 26.00 \\
Methanol & 29.70 \\
Water & 48.20 \\
\hline
\end{tabular}

alcohols, and that by one of us [31] for ABS in a range of liquid organic solvents. It seems that $K_{\dot{j}}^{2}$ $\left(=E R_{\mathrm{i}}\right)$ is a smooth function of $\delta_{\mathrm{s}}$ and possesses a minimum in the region where $\delta_{\mathrm{s}} \approx \delta_{\mathrm{p}}, \delta_{\mathrm{p}}$ being the solubility parameter of the polymer. For reference, a similar curve for the matrix material, polystyrene, is also shown in the same figure. The solvent solubility parameter for PS is about 19.5 $\left(\mathrm{MJ} \mathrm{m}^{-3}\right)^{1 / 2}$ and that for the glass-filled plastic is $19.8\left(\mathrm{MJ} \mathrm{m}^{-3}\right)^{1 / 2}$. As is obvious from that figure, the glass fibres have the effect of improving the fracture resistance of the matrix. Since the environmental experiments have only been performed at $296 \mathrm{~K}$, and since $K_{\mathrm{i}}$ is a strong function of temperature, the geometry of the correlation curve will be somewhat affected at other temperatures. However, as explained in [31], $K_{\mathbf{i}}^{2}$ should always be a minimum at $\delta_{\mathrm{s}} \approx \delta_{\mathrm{p}}$ independent of temperature. Perhaps the significance of these exploratory results is the indication that the $\delta_{\mathrm{s}}$ versus $K_{\mathrm{i}}^{2}$ (= $E R_{\mathrm{i}}$ ) correlation is useful not only for describing environmental cracking of glassy polymers such as PMMA, ABS, and PS, but can also be extended to glass-filled thermoplastic composites.

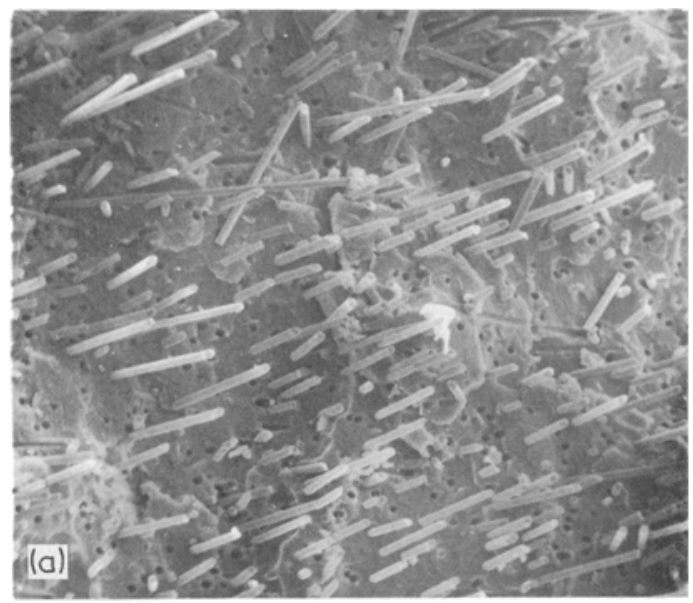

It is interesting to compare the fracture mechanisms of the glass-filled polystyrene composite and the plain polystyrene in these various organic solvents. A summary of these results is presented in the next section.

\section{SEM studies for fracture in plain and glass-filled polystyrenes}

\subsection{Temperature effects}

The characteristic fracture surfaces of plain poly. styrene have been described by others $[32-35]$. In general, there are three different features [32]: the mirror area (which represents the region of slow, stable crack growth), the lined area and the rough area (for unstable crack propagation). In our present experiments, these three features have been observed in plain polystyrene for temperatures below $363 \mathrm{~K}$. However, at $363 \mathrm{~K}$, the fracture surface produced is different. Only the slow crack propagation "mirror area" is observed, there are no traces of "lined" and "rough" areas.

Fig. 10a and $b$ show the fracture surfaces (near crack initiation) of the glass-filled styrene at 296 and $363 \mathrm{~K}$ respectively. Both fracture surfaces are characterized by domain structures, but those fractured at $363 \mathrm{~K}$ display more ductility with drawn out edges. This is not unexpected since at higher temperatures, the matrix material (i.e. styrene) flows more easily. Note that on these fracture surfaces, the "lined" areas such as observed in plain polystyrene do not appear to exist.

\subsection{Absorption of organic solvent effects}

Since the organic liquids used in the fracture experiments react differently with the polystyrene, it



Figure 10 Characteristic fracture surfaces for glass-filled PS (a) at $296 \mathrm{~K}$ and (b) at $363 \mathrm{~K}$. Crack direction: left to right (X70). 


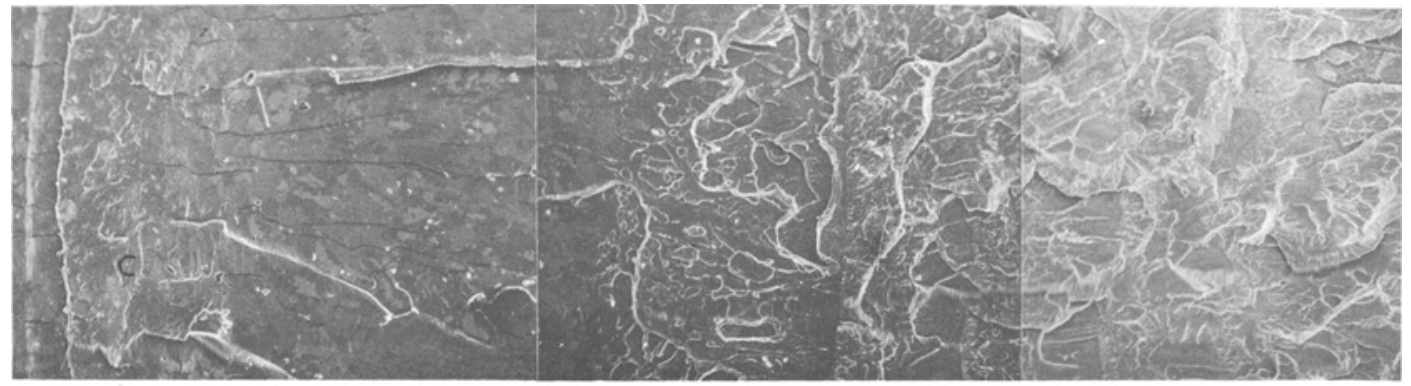

mirror area

Figure 11 A complete fracture surface of PS in methanol, showing the mirror, lined and rough areas. Crack direction left to right $(\times 25)$.

is better to distinguish fracture surfaces produced by "crazing" agents and by "solvents". When crazing liquids (such as methanol, toluene, isopropanol and water) are involved, the three characteristic features (i.e.mirror, lined and rough areas) observed previously are preserved. For example, Fig. 11 shows a characteristic surface occurring in methanol. It is interesting to note that in the "mirror" area near the initiation region (marked "C"), local ductile drawing, together with cavitation of the polymer, are predominant. These features are shown in Fig. 12a and b.

However, fracture surfaces produced in solvents, such as acetone and benzene, are rather featureless. It is possible that the solution effect of the solvent has removed significant fracture details on the surface.



The typical fracture surfaces of the glass-filled polystyrene produced in crazing agents are also characterized by ductile drawing of the matrix material. But in the case of fracture in solvents, matrix drawing does not appear to have occurred. Instead, crazes and matrix cracking are often observed on the fracture surfaces.

\section{Conclusions}

The rate/temperature dependent fracture behaviour of both the plain/glass-filled PS has been reported in earlier sections of this paper. In summary, the $K_{\mathrm{c}}(\dot{a}, T)$ data obtained experimentally for both materials are shown to follow closely those relationships given by the Williams/Marshall relaxation-controlled crack growth analysis [1] and the $R\left(=K_{\mathrm{c}}^{2} / E\right)$-biased [7] or $K$-biased rate models.

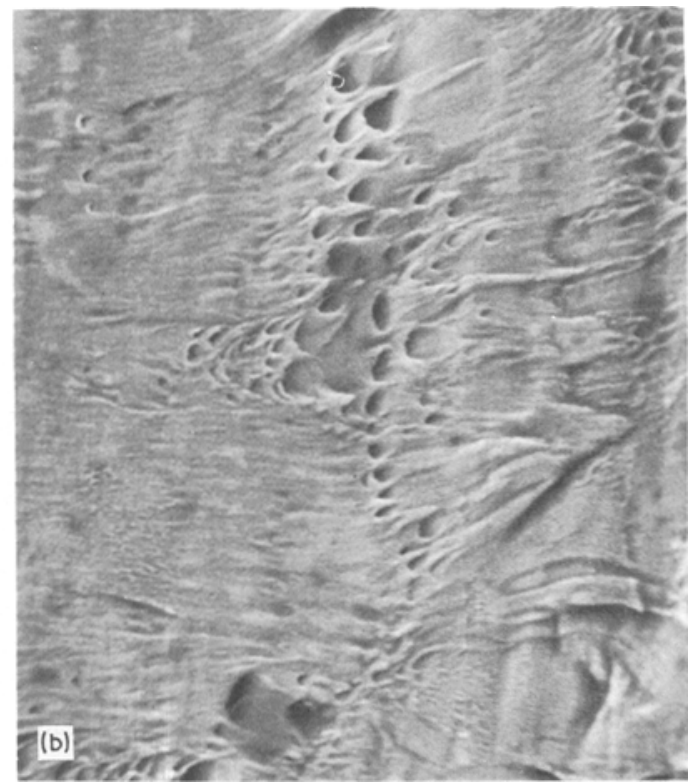

Figure 12 Detailed views of fracture near region " $\mathrm{C}$ " in Figure 11, showing environment-enhanced matrix drawing and cavitation. All propagating directions left to right $[\times 680$ in (a), $\times 2300$ in (b) $]$. 
Thus, it is difficult to assess which of these theories is best for describing the rate/temperature dependent fracture behaviour observed. Crack propagation in plain/glass-filled PS is controlled by a $\beta$-relaxation molecular process associated with crazing. The activation energies obtained are some 200 to 220 $\mathrm{kJ} \mathrm{mol}^{-1}$ for both materials.

It is found that although the C.O.D. for both plain/glass-filled PS has a constant magnitude at a given temperature, which is independent of crack speed, the C.O.D. does increase with decreasing temperature. This difference may be as much as $60 \%$.

The crack instabilities observed for plain PS can be explained fully by the isothermal-adiabatic transitions at the crack tip. Reasonable agreement between theoretical and experimental instability crack speeds has been obtained.

The $K_{\mathrm{i}}^{2}$ versus $\delta_{\mathrm{s}}$ plots are shown to be useful in describing fracture initiation resistances of plain as well as glass-filled PS in various liquid environments. These $K_{\mathrm{i}}^{2}-\delta_{\mathrm{s}}$ correlations provide good estimates for the solubility parameters of both materials.

Other testing conditions being equal, the glassfilled thermoplastic is shown to display better resistance to crack propagation than the plain polymer.

\section{Acknowledgement}

We are most grateful to Thermofil Company (Michigan, USA) for supplying the ready-mixed glass-filled and plain polystyrene pellets for the experimental investigation reported in this paper.

\section{References}

1. J. G. WILliams and G. P. MARSHAll, Proc. Roy. Soc. A342 (1975) 55.

2. I. D. GRAHAM et $a l$, , Proceedings of the Dynamic Crack Propagation Conference, Lehigh University, (1972).

3. G. P. MARSHALL, L. H. COUTTS and J. G. WILliaMS, J. Mater. Sci. 9 (1974) 1409.

4. E. H. ANDREWS and L. BEVAN, "Physical Basis of Yield and Fracture" (Institute of Physics, London, 1966) p. 209.

5. E. H. ANDREWS, G. M. LEVY and J. WILLIS, $J$. Mater. Sci. 8 (1973) 1000.
6. Y. W. MAI, ibid, 10 (1975) 943.

7. A. G. ATKINS, C. S. LEE and R. M. CADDELL, ibid. 10 (1975) 1381.

8. F. A. JOHNSON and J. C. RADON, Engr. Fract. Mech. 4 (1972) 555.

9. H. W. LIU, ASME paper no. 69-Met-6 (1969).

10. A. KELLY and W. R. TYSON, "High Strength Materials", edited by V. F. Zackay, (Wiley, New York, 1965) p.578.

11. L. H. LEE, Polymer Engg. Sci. 9 (1969) 213.

12. R. E. LAVENGOOD, ibid 12 (1972) 48.

13. J. K. LEES, ibid 8 (1968) 186.

14. Idem, ibid 8 (1968) 195.

15. P. E. CHEN, ibid 11 (1971) 51.

16. L. E. NIELSEN, J. App. Polymer Sci. 10 (1966) 97.

17. A. WAMBACH, K. TRACHTE and A. DIBENEDetTo, J. Comp. Mat. 2 (1968) 266.

18. R. P. KAMBour et al., J. Appl. Polymer Sci. Poly. mer Phys. Ed. 11 (1973) 1879.

19. W. F. BROWN and J. E. SRAWLEY, ASTM STP 410 (1966).

20. G. P. MARSHALL, L. E. CULVER and J. G. WILLIAMS, Int. J. Fracture 9 (1973) 295.

21. J. G. WILLIAMS, J. C. RADON and C. E. TURNER, Polymer Engg. Sci. 8 (1968) 130.

22. G. R. IRWIN, Appl. Mat. Res. 3 (1964) 65.

23. J. G. WILLIAMS, Int. J. Fract. Mech. 8 (1972) 393.

24. J. A. KIES and A. B. J. CLARK, Proceedings of the Second International Conference on Fracture, Brighton, England (1966) p.483.

25. T. E. BRADY and G. S. Y. YEH, J. Macromol. Sci. Phys. B9 (1974) 659.

26. G. S. Y. YEH, private communication.

27. S. M. WIEDERHORN, J. Amer. Ceram. Soc. $\mathbf{5 0}$ (1967) 407.

28. S. W. FREIMAN, D. R. MULVILLE and P. W. MAST, J. Mater. Sci. 8 (1973) 1527.

29. H. BURREL and E. H. IMMERGUT, "Polymer Handbook" (Interscience, New York, 1966).

30. E. H. ANDREWS and L. BEVAN, Polymer 13 (1972) 337.

31. Y. W. MAI, J. Mater. Sci. 11 (1976) 303.

32. R. J. BIRD, J. MANN, G. POGANY and G. ROONEY, Polymer 7 (1966) 307.

33. M. J. DOYLE, A. MARANCI, E. OROWAN and S. T. STORK, Proc. Roy. Soc. A329 (1972) 137.

34. D. HULL, J. Mater. Sci. 5 (1970) 357.

35. P. BEAHAN, M. BEAVIS and D. HULL, Proc. Roy. Soc. A323 (1975) 525.

36. Y. W. MAI and C. GURNEY, Phys. Chem. Glasses 16 (1975) 70.

37. Y. W. MAI and A. G. ATKINS, Met. Trans. 6A (1975) 2161.

Received 26 August and accepted 14 October 1975. 